\title{
MEDIAÇÃO DA INFORMAÇÃO: UM OLHAR SOBRE O PORTAL LTi A PARTIR LITERATURA INDEXADA NA BRAPCI
}

\author{
MEDIACIÓN DE LA INFORMACIÓN: UNA MIRADA AL \\ PORTAL LTi DE LA LITERATURA INDEXADAS EN BRAPCI
}

Isa Maria Freire - isafreire@globo.com Doutora em Ciência da Informação pela Universidade Federal do Rio de Janeiro (UFRJ). Docente permanente no Programa de Pós-Graduação em Ciência da Informação da Universidade Federal da Paraíba (UFPB).

Coordenadora da rede de projetos do Laboratório de Tecnologias Intelectuais - LTi.

\section{RESUMO}

Introdução: Apresenta resultados de pesquisa exploratória sobre a produção científica publicada sobre a temática <mediação da informação > no campo da Ciência da Informação, no Brasil, com vistas à identificação de abordagens teóricas e epistemológicas.

Objetivo: Observar, na literatura indexada na Base de Dados Referencial de Artigos de Periódicos em Ciência da Informação, os indícios de abordagens sobre a temática <mediação da informação >, no Brasil.

Metodologia: A pesquisa utilizou o método indiciário e o procedimento de brauseio para buscar a produção científica sobre a temática <mediação da informação> na Brapci, selecionando 13 artigos, publicados em nove periódicos, que apresentam o termo de busca nos títulos e palavras-chave, para compor uma amostra do território da literatura, onde os indícios de abordagens foram observados.

Resultados: Observamos que os artigos que compõem a amostra apresentam os indícios de várias temáticas relacionadas a <mediação da informação>, destacando-se: <mediação humana>, <leitura>, <ação cultural>, <cultura>, <competência informacional>, <fluxos de informação >, <tecnologia da informação e comunicação $>$.

Conclusões: Cotejamos os resultados da nossa observação com aqueles obtidos na pesquisa de Gomes (2010) sobre a produção na temática <mediação da informação>, embora usando metodologia diferente da adotada neste exercício, encontrando similaridades que tanto confirmam nossos resultados quanto ratificam a metodologia que adotamos. 
Palavras-chaves: Mediação da informação. Literatura científica - Brasil. Paradigma indiciário. Regime de informação. Brapci.

\section{INTRODUÇÃO}

A presente comunicação compartilha o processo e os resultados de exercício de busca dos indícios de abordagens da temática <mediação da informação>, na literatura científica brasileira indexada pela Base de Dados Referencial de Artigos de Periódicos em Ciência da Informação - Brapci, publicada pela Universidade Federal do Paraná. Trata-se de mais um exercício provocado por reflexões epistemológicas acerca das ações de informação em curso no Projeto Laboratório de Tecnologias Intelectuais - LTi, seus estratos e modalidades.

Em exercício anterior abordamos a temática <responsabilidade social>, seguindo indícios conceituais no território da literatura indexada pela Brapci e que revelaram a produtividade da produção científica sobre o tema (FREIRE, 2013). No presente exercício, buscamos as pistas de abordagens com modelos que nos ajudem a refletir sobre a tipologia e as características dos dispositivos e artefatos de mediação da informação em curso no Projeto LTi. Neste contexto, a premissa da responsabilidade social de facilitar a transmissão do conhecimento para aqueles que dele necessitam, proposta por Wersig e Neveling para a Ciência da Informação, em 1975, e adotada no Projeto, se materializa em ações de informação na comunidade acadêmica e seus resultados são compartilhados mediante serviços e produtos de informação disponíveis no Portal LT $\boldsymbol{i}^{1}$.

Ambos os exercícios teórico-epistemológicos se inserem no âmbito da pesquisa de produtividade "Ação de informação no Laboratório de Tecnologias Intelectuais - LTĩ', em desenvolvimento na Universidade Federal da Paraíba, no que diz respeito ao contexto das questões que orientam as ações de informação no campo da pesquisa. No presente exercício, a questão principal diz respeito aos dispositivos e artefatos de informação mediados pelo Portal LTi e, nesse contexto, às abordagens e aplicações do conceito de mediação da informação.

\footnotetext{
${ }^{1}$ http://dci.ccsa.ufpb.br/lti
} 
Para identificar as publicações e autores que abordam essa temática, bem como os temas de suas contribuições no território da literatura, recorremos ao método indiciário, aplicado por Ginzburg (1989), e ao procedimento de brauseio, descrito por Araújo (1994), tomando como primeiros indícios o quadro das tags que representam "termos associados à descrição de busca para filtrar informações relevantes", na interface de resultados da Brapci.

Destarte, orientamos nosso olhar sobre o território a partir do modelo de regime de informação de González de Gómez (2003b, p. 61), para o qual a informação é definida como "ações de informação, as quais remetem aos atores que as agenciam, aos contextos e situações em que acontecem e aos regimes de informação em que se inscrevem". Nesse modelo, as ações de informações se desenvolvem em domínios diferentes do regime de informação, como González de Gómez descreve em sua teleologia das ações de informação (2003a) e Freire (2012) caracteriza, em sua análise dos estratos e modalidades das ações de informação no LTi.

A partir da reunião dos indícios sobre disponíveis na literatura em uma rede conceitual, esperamos formular hipóteses de trabalho sobre os processos de mediação da informação no Projeto e oferecer novas questões para abordar o problema que inspirou esta pesquisa, qual seja, a caracterização dos tipos de mediação da informação propiciados pela interface virtual do LTi. Certamente será uma resposta provisória, condicionada pelo tempo, espaço e instrumentos da pesquisa. Mas esperamos provocar o interesse que propiciem o uso do método indiciário em incursões sobre outras temáticas, no território da literatura da Ciência da Informação.

\section{CAÇANDO O INVISÍVEL}

Entendemos este exercício como uma narrativa da "caçada" ao nosso objeto de pesquisa - a produção científica sobre <mediação da informação> indexada na Brapci, corroborando a visão de Alves (1994, p. 39) sobre o cientista como "caçador do invisível na realidade visível", e a observação de Sagan (1999, p. 301) sobre os Kung San, grupo de caçadores primitivos: "suas habilidades de rastreamento são ciência em ação". No presente trabalho usamos uma e outra metáfora como 
justificativas para o método que utilizamos para buscar as pistas de abordagens teóricas no território da literatura sobre <mediação da informação>.

\section{1 Método e Instrumento}

Em ensaio publicado em 1989, o historiador Carlo Ginzburg mostra como no final do século XIX "emergiu silenciosamente no âmbito das ciências humanas um modelo epistemológico ao qual até agora não se prestou suficiente atenção", um "paradigma indiciário" tão antigo que remontaria aos primórdios da própria evolução da humanidade (GINZBURG, 1989 p. 143). Para o autor, esse as origens desse método se encontram na atividade primitiva da caça:

Por milênios o homem foi caçador. Durante inúmeras perseguições, ele aprendeu a reconstruir as formas e movimentos das presas invisíveis pelas pegadas na lama, ramos quebrados, bolotas de esterco, tufos de pelos, plumas emaranhadas, odores estagnados. Aprendeu a farejar, registrar, interpretar e classificar pistas infinitesimais como fios de barba. Aprendeu a fazer operações mentais complexas com rapidez fulminante, no interior de um denso bosque ou numa clareira cheia de ciladas. Gerações e gerações de caçadores enriqueceram e transmitiram esse patrimônio cognoscitivo. Na falta de uma documentação verbal para se por ao lado das pinturas rupestres e dos artefatos, podemos recorrer às narrativas de fábulas, que do saber daqueles remotos caçadores transmitem-nos às vezes um eco, mesmo que tardio e deformado. (GINZBURG, 1989, p. 151).

Desse modo, o paradigma indiciário se traduz em um saber de tipo venatório, caracterizado pela capacidade de descrever uma realidade complexa, que não seria cientificamente experimentável, a partir de dados aparentemente irrelevantes. Ginzburg (1989) acrescenta que esses dados são sempre dispostos pelo caçador [observador] de modo tal que se expresse como sequência narrativa cuja formulação mais simples poderia ser descrição da passagem de pessoas ou animais em algum território. Nesse sentido, o autor defende que a própria ideia de narração (contar uma história, descrever situações e comportamentos), distinta de outras formas de expressão como o sortilégio, o exconjuro ou a invocação, teria nascido numa sociedade de caçadores, a partir da experiência da decifração das pistas: "O caçador teria sido o primeiro a 'narrar uma história' porque era o único capaz de ler, 
nas pistas mudas (se não imperceptíveis) deixadas pela presa, uma série coerente de eventos" (GINZBURG, 1989, p. 152).

Ginzburg (1989, p.170) transporta essa competência para a decifração e interpretação de pistas para o campo científico, comparando os fios que compõem uma pesquisa desenvolvida sob o paradigma indiciário aos fios de um tapete - 0 que lembra a abordagem da rede conceitual proposta por Wersig (1993) para a Ciência da Informação. No modelo indiciário, colocados os conceitos básicos e definido o campo onde se realiza a investigação, enfim, reunidos os indícios ou pistas do objeto de estudo, o observador verá tomar forma uma "trama densa e homogênea" cujo contexto será tecido no tear do quadro de referência teórico. $E$ tanto quanto no território, a coerência do padrão identificado pela visão do observador é verificável "percorrendo-se o tapete [ou espaço] com os olhos em várias direções" (GINZBURG, 1989, p.170). Nesse processo de investigação, seja no território da pesquisa, como "caçador do invisível", ou no tear, como "tecelão de sentidos", o observador estará buscando os indícios que apontem para as trilhas da caça ou para os fios da trama.

Araújo (1994) chama esse processo de brauseio. Em seu estudo dos sistemas de recuperação da informação a autora descreve esse processo de busca de informação através de indícios, que considera uma das modalidades de busca mais importantes em um sistema de recuperação da informação e é estudado no contexto do subsistema de estratégia de busca. E esclarece que o termo "browsing", de onde adaptou "brauseio", é aplicado a ações de andar a esmo, ou deambular, em uma biblioteca ou centro de documentação folheando documentos ao acaso, colhendo "flashes" de informação de todos os tipos. Ainda de acordo com Araújo (1994), o termo é derivado do comportamento de busca de alimento do cervo que ao selecionar os brotos mais tenros para se alimentar o faz através de um brauseio - 0 que dá a esse termo a conotação de seleção de informações válidas e úteis.

Outra forma de definir o processo de brausear é "a arte de não se saber o que se quer até que se o encontre" (ARAÚJO, 1994, p.189). O brauseio é essencialmente visual e tem um forte componente de "acesso direto", podendo ser associado com formas e padrões em termos de imagens e distribuição do texto numa página ou numa tela de computador. Trata-se de uma atividade de busca, ocasionada por uma necessidade ou interesse de informação percebido, como neste caso de buscar indícios da produção científica brasileira sobre <mediação da 
informação> no território da literatura indexada pela Brapci, de modo a revelar abordagens teóricas que subsidiem uma reflexão sobre tipologia e características dos serviços e produtos de informação disponibilizados no Portal LTi.

\section{2 Um Olhar Sobre o Território}

A Base de Dados Referenciais de Artigos de Periódicos em Ciência da Informação (Brapci) representa o território da literatura para o presente exercício. A Brapci é o produto de informação do projeto de pesquisa "Opções metodológicas em pesquisa: a contribuição da área da informação para a produção de saberes no ensino superior", cujo objetivo é subsidiar estudos e propostas na área de Ciência da Informação, fundamentando-se em atividades planejadas institucionalmente. Com esse propósito, foram identificados os títulos de periódicos da área de Ciência da Informação $(\mathrm{Cl})$ e indexados seus artigos, constituindo-se a base de dados referenciais. Atualmente, a Brapci disponibiliza referências e resumos de 8.303 textos publicados em 37 periódicos nacionais impressos e eletrônicos da área de $\mathrm{Cl}$, sendo 26 vigentes e 11 históricos (BRAPCI, 2013).

Certamente, como diz em seu texto na página inicial, a Brapci "está contribuindo para estudos analíticos e descritivos sobre a produção editorial de uma área em desenvolvimento", como é nosso propósito neste exercício, "ao subsidiar com uma ferramenta dinâmica os alunos, professores e pesquisadores da área" (BRAPCl, 2013). Nesse sentido, certamente a Brapci "amplia o espaço documentário permitido ao pesquisador, facilita a visão de conjunto da produção na área, ao mesmo tempo [em] que revela especificidades do domínio científico", uma vez que "Os saberes e as pesquisas publicados e organizados para fácil recuperação clarificam as posições teóricas dos pesquisadores" (BRAPCl, 2013). Foi o que observamos, na prática da pesquisa no território da literatura.

No presente exercício, buscamos artigos, em todos os campos e em todo o período (1970-2013), utilizando inicialmente <mediação> como termo de busca. Foram recuperados 147 artigos, sendo 2013 o ano mais recente e 1980 o ano mais antigo. Em seguida, fizemos nova busca, utilizando o termo composto <mediação da informação>, recuperando 37 artigos, sendo o mais recente de 2013 e o mais antigo de 1995. Observando que todos os artigos recuperados na segunda busca estavam contidos na primeira, tomamos a iniciativa de restringir ainda mais nosso território da 
literatura, identificando entre os 37 artigos aqueles que apresentavam o termo <mediação da informação> no título e nas palavras-chave. Foram identificados 13 artigos, que constituem a amostra de artigos nos quais buscaremos abordagens teóricas que contribuam para nossa reflexão sobre os processos de mediação da informação em curso no Projeto LTi.

A partir dos indícios observados no território da literatura, organizamos quadros com os periódicos e autores que apresentam o termo <mediação da informação> nos títulos e palavras-chave dos artigos recuperados na Brapci. Nos resultados, produzimos uma classificação das temáticas representadas nos títulos e palavras-chave à luz das ações de informação, como propõe González de Gómez (2003a), com vistas a sua interpretação no contexto das ações de informação em curso no Projeto LTi. Elaboramos, também a partir dos indícios das temáticas reveladas na pesquisa, uma rede conceitual tendo como atrator o termo <mediação da informação>. A seguir, apresentamos os quadros com a descrição dos artigos selecionados como pertinentes e relevantes nosso propósito com este exercício, os quais foram publicados em nove periódicos no período 2008-2013.

Quadro 1 - Amostra: periódicos, quantidade de artigos, ano de publicação

\begin{tabular}{|l|c|c|}
\hline \multicolumn{1}{|c|}{ PERIÓDICOS } & $\begin{array}{c}\text { Qtde. } \\
\text { ARTIGOS }\end{array}$ & $\begin{array}{c}\text { ANO DE } \\
\text { PUBLICAÇÃo }\end{array}$ \\
\hline Biblionline & 2 & 2012,2011 \\
\hline Informação \& Informação & 2 & 2011,2008 \\
\hline $\begin{array}{l}\text { Informação \& Sociedade: Estudos } \\
\text { Informação }\end{array}$ & 2 & 2011,2010 \\
\hline $\begin{array}{l}\text { Em Questão: Revista da Faculdade de Biblioteconomia e } \\
\text { Comunicação da UFRGS }\end{array}$ & 1 & 2010,2009 \\
\hline $\begin{array}{l}\text { Encontros Bibli: Revista Eletrônica de Biblioteconomia e } \\
\text { Ciência da Informação }\end{array}$ & 1 & 2012 \\
\hline $\begin{array}{l}\text { Ponto de Acesso: revista do Instituto de Ciência da } \\
\text { Informação da UFBA }\end{array}$ & 1 & 2012 \\
\hline $\begin{array}{l}\text { InCID: Revista de Ciência a Informação e Documentação } \\
\text { Ciência da Informação }\end{array}$ & 1 & 2010 \\
\hline
\end{tabular}

Fonte: Brapci. Dados da pesquisa, 2014. N= número de artigos da amostra. 
No grupo de artigos selecionados, a publicação mais antiga data de 2008, no periódico Informação \& Informação, e as mais recentes datam de 2012, distribuídas em três periódicos: Biblionline, Encontros Bibli e Ponto de Acesso . O ano mais produtivo no intervalo de tempo foi 2011, quando foram publicados cinco artigos com o termo <mediação da informação> no título e nas palavras-chave, em cinco periódicos: Biblionline, Informação \& Informação, Informação \& Sociedade, Em Questão e Ciência da Informação. Os periódicos que mais publicaram no período foram: Biblionline, Informação \& Informação, Informação \& Sociedade e Tendências da Pesquisa Brasileira em Ciência da Informação.

No quadro a seguir, descrevemos os títulos dos artigos publicados selecionados para compor a amostra. 
Quadro 2 - Amostra: periódicos, títulos dos artigos, ano da publicação

\begin{tabular}{|c|c|c|}
\hline PERIÓDICOS & TÍTULOS DOS ARTIGOS & ANO \\
\hline \multirow[t]{2}{*}{ Biblionline } & $\begin{array}{l}\text { A mediação da informação na rede de bibliotecas do } \\
\text { ministério público federal: um mapeamento sobre o } \\
\text { uso dos serviços de referência online disponíveis no } \\
\text { sistema pergamum }\end{array}$ & 2012 \\
\hline & $\begin{array}{l}\text { O marketing e a arquitetura da informação para web } \\
\text { no contexto do processo de mediação da informação }\end{array}$ & 2011 \\
\hline \multirow{2}{*}{ Informação \& Informação } & $\begin{array}{l}\text { Mediação da informação em websites de bibliotecas } \\
\text { universitárias brasileiras: referencial teórico }\end{array}$ & 2011 \\
\hline & $\begin{array}{l}\text { Mediação da informação no âmbito do mercado de } \\
\text { capitais }\end{array}$ & 2008 \\
\hline \multirow[b]{2}{*}{ Informação \& Sociedade } & $\begin{array}{l}\text { Mediação tecnológica da informação no parlamento: } \\
\text { estudo de uma assembléia legislativa no contexto } \\
\text { brasileiro }\end{array}$ & 2011 \\
\hline & $\begin{array}{l}\text { A mediação da informação pelas bibliotecas } \\
\text { universitárias: um mapeamento sobre o uso dos } \\
\text { dispositivos de comunicação na web }\end{array}$ & 2010 \\
\hline \multirow{2}{*}{$\begin{array}{l}\text { Tendências da Pesquisa } \\
{[\ldots]}\end{array}$} & $\begin{array}{l}\text { Tendências de pesquisa sobre mediação, circulação e } \\
\text { apropriação da informação no brasil: estudo em } \\
\text { periódicos e anais dos enancib (2008-2009) }\end{array}$ & 2010 \\
\hline & Mediação da informação e múltiplas linguagens & 2009 \\
\hline Em Questão [...] & $\begin{array}{l}\text { Disseminação da informação em empresas de capital } \\
\text { aberto e os processos de mediação da informação }\end{array}$ & 2011 \\
\hline Encontros Bibli $[\ldots]$ & $\begin{array}{l}\text { A mediação da informação através da comunidade } \\
\text { virtual Anobii: um estudo de caso }\end{array}$ & 2012 \\
\hline Ponto de Acesso & $\begin{array}{l}\text { Palavras-chave: possibilidades de mediação da } \\
\text { informação }\end{array}$ & 2012 \\
\hline $\operatorname{lnCID}[\ldots]$ & $\begin{array}{l}\text { Mediação da Informação no fazer do bibliotecário e } \\
\text { seu processo em bibliotecas universitárias no âmbito } \\
\text { das ações culturais }\end{array}$ & 2010 \\
\hline Ciência da Informação & $\begin{array}{l}\text { Mediação da informação para agentes sociodigitais: o } \\
\text { salto }\end{array}$ & 2011 \\
\hline
\end{tabular}
$\mathrm{N}=13$.

Fonte: Brapci. Dados da pesquisa, 2014. Mantida a grafia original das palavras dos títulos. 
Foram observados, nos títulos, os termos que descrevem o propósito ou a especificação da temática de cada artigo, os quais representam indícios das abordagens sobre <mediação da informação> disponíveis na literatura, a saber:

Rede de bibliotecas; serviços de referência online; processo de mediação da informação na web; bibliotecas universitárias - websites; mercado de capitais; mediação tecnológica da informação; dispositivos de comunicação na web; estudo cientométrico; múltiplas linguagens; comunidade virtual; palavraschave; arquitetura da informação - web; profissional bibliotecário; ações culturais

Depois de organizarmos os indícios da temática contidos nos títulos, elaboramos um quadro com as palavras-chave dos artigos publicados nos periódicos: 
Quadro 3 - Amostra: periódicos e palavras-chave

\begin{tabular}{|c|c|c|}
\hline PERIÓDICOS & PALAVRAS-CHAVE & ANO \\
\hline \multirow[t]{2}{*}{ Biblionline } & $\begin{array}{l}\text { mediação da informação. Serviço de Referência } \\
\text { online. } \\
\text { Sistema Pergamum. Ministério Público Federal - } \\
\text { Rede de Bibliotecas }\end{array}$ & 2012 \\
\hline & $\begin{array}{l}\text { Marketing. Arquitetura da Informação para Web. } \\
\text { Mediação da informação. Usuários de informação. } \\
\text { Multidisciplinaridade. }\end{array}$ & 2011 \\
\hline \multirow[t]{2}{*}{$\begin{array}{l}\text { Informação \& } \\
\text { Informação }\end{array}$} & $\begin{array}{l}\text { mediação da informação. bibliotecas universitárias. } \\
\text { websites. tecnologias da informação e da } \\
\text { comunicação }\end{array}$ & 2011 \\
\hline & $\begin{array}{l}\text { mediação da informação. mercado de capitais. } \\
\text { Gestão da Informação. fluxos de informação. } \\
\text { governança corporativa }\end{array}$ & 2008 \\
\hline \multirow{2}{*}{$\begin{array}{l}\text { Informação \& } \\
\text { Sociedade }\end{array}$} & $\begin{array}{l}\text { Informação e comunicação. Mediação da } \\
\text { informação. Fluxo de informação. Parlamento } \\
\text { eletrônico }\end{array}$ & 2011 \\
\hline & $\begin{array}{l}\text { Biblioteca universitária - Mediação da Informação. } \\
\text { Ciência da Informação. Biblioteca universitária - } \\
\text { Leitura. Biblioteconomia. Biblioteca universitária - } \\
\text { Escrit }\end{array}$ & 2010 \\
\hline \multirow[t]{2}{*}{$\begin{array}{l}\text { Tendências da } \\
\text { Pesquisa }[\ldots]\end{array}$} & $\begin{array}{l}\text { mediação da informação. Circulação da } \\
\text { informação. apropriação da informação. Ciência da } \\
\text { Informação - Brasil }\end{array}$ & 2010 \\
\hline & $\begin{array}{l}\text { mediação da informação. Informação. leitura } \\
\text { informacional. interferência }\end{array}$ & 2009 \\
\hline Em Questão [...] & $\begin{array}{l}\text { Disseminação da informação. Mediação da } \\
\text { informação. processos de mediação. Gestão da } \\
\text { informação. Governança corporativa }\end{array}$ & 2011 \\
\hline Encontros Bibli [...] & $\begin{array}{l}\text { leitura. tecnologia. Mediação da informação. } \\
\text { comunidades virtuais. Anobii }\end{array}$ & 2012 \\
\hline Ponto de Acesso & $\begin{array}{l}\text { ciências sociais aplicadas. Ciência da Informação. } \\
\text { mediação da informação. análise documentária. } \\
\text { palavras-chave. representação da mediação }\end{array}$ & 2012 \\
\hline $\ln C I D[\ldots]$ & $\begin{array}{l}\text { mediação da informação. cultura. ação cultural. } \\
\text { animação cultural }\end{array}$ & 2010 \\
\hline Ciência da Informação & $\begin{array}{l}\text { Mediação da informação. Competência } \\
\text { informacional. Inclusão sociodigital. Mediação } \\
\text { humana. Letramento Informacional. }\end{array}$ & 2011 \\
\hline
\end{tabular}

Fonte: Brapci. Dados da pesquisa, 2014. Mantida a grafia original das palavras-chave. $\mathrm{N}=13$. 
Descrevemos, a seguir, as palavras-chave que representam o conteúdo dos artigos e constituem indícios valiosos sobre as abordagens do tema <mediação da informação>, no território da literatura indexada pela Brapci:

serviço de referência online; rede de bibliotecas; arquitetura da informação - web; usuários da informação; multidisciplinaridade; bibliotecas universitárias; websites; tecnologias da informação e da comunicação; mercado de capitais; gestão da informação; fluxos de informação; governança corporativa; informação e comunicação; fluxo de comunicação; parlamento eletrônico; circulação da informação; biblioteconomia; biblioteca universitária - leitura; apropriação da informação; leitura informacional; interferência; disseminação da informação; leitura; tecnologia; comunidades virtuais; análise documentária; palavras-chave; representação da mediação; cultura; ação cultural; animação cultural; competência informacional; inclusão sociodigital; mediação humana; letramento informacional

Os indícios da temática que identificamos no território da literatura podem ser cotejados com os resultados do estudo de Gomes (2010) sobre as "tendências de pesquisa sobre mediação, circulação e apropriação da informação no Brasil", realizado em periódicos e anais dos Encontros Nacionais de Pesquisa em Ciência da Informação no período 2008-2009. Segundo a autora,

Os resultados indicam crescimento do número de pesquisas sobre mediação humana, cultural e tecnológica; geração, produção, comunicação e apropriação da informação; busca, acesso e uso da informação; linguagens, produção simbólica e memória; leitura; necessidades e comportamento informacional, competência em informação; redes e fluxos de informação e inclusão digital. [...] (GOMES, 2010, p. 85, Itálico nosso)

As aproximações com os indícios que identificamos na nossa incursão no território da literatura, dizem respeito principalmente aos termos <mediação humana>, <ação cultural>, <mediação tecnológica>, <competência em informação>, <fluxos de informação>, <leitura>, <informação e comunicação>. Contudo, podemos observar que os indícios representados por termos descritivos da temática no título e nas palavras-chave alcançam maior abrangência, permitindo o mapeamento de várias trilhas a serem percorridas na identificação de abordagens que fundamentem nossa reflexão sobre os artefatos de mediação da informação disponíveis no Portal LTi. Esse mapeamento inicial já nos permite desenhar uma primeira aproximação da rede conceitual relacionada ao tema <mediação da informação>, em consonância com o modelo teórico do Projeto LTi. 


\section{3 Rede Conceitual}

No campo da Ciência da Informação, a abordagem de problemas tem sido uma característica metodológica, como aponta Saracevic (1996, p.41), esclarecendo que:

[...] Um campo é definido pelos problemas que são propostos e a ciência da informação é definida como um campo englobando tanto a pesquisa científica quanto a prática profissional, pelos problemas que propõe e pelos métodos que escolheu, ao longo do tempo, para solucioná-los.

O autor argumenta que os problemas de informação - um fenômeno da comunicação humana - não podem ser abordados dentro de uma única área da atividade científica. Por isso, torna-se necessário o desenvolvimento, na Ciência da Informação, de abordagens teóricas e metodológicas que favoreçam a interdisciplinaridade e permitam o relacionamento da ciência da informação com outros campos científicos. Para Saracevic (1996, p.60), "trocas significantes estão acontecendo entre vários campos científicos que abordam os mesmos problemas de informação, ou semelhantes, de formas bastante diferentes. A ciência da informação definitivamente deveria unir esses campos"

Uma proposta nesse sentido foi apresentada por Wersig durante uma conferência científica de Tampère, Finlândia (1991), cujo texto publicou no periódico Information Processing \& Management, em 1993. O autor sugere que o campo da Ciência da Informação poderia vir a tornar-se "algum tipo de sistema de navegação conceitual" para abordagem dos problemas da informação, na sociedade contemporânea (WERSIG, 1993, p.238). O autor caracteriza a Ciência da Informação como ciência pós-moderna justamente por lidar com problemas, sugerindo que o trabalho desse novo tipo de ciência não se restringiria a enunciados e conceitos, mas se ampliaria até a proposição de estratégias para solução de problemas.

Wersig (1993) apresenta sua abordagem dos problemas de informação para a Ciência da Informação com três tipos de modelos, destacando o modelo de rede conceitual: neste, os conceitos fundamentais, "se constituem semelhantemente a ímãs, ou 'atratores', atraindo os materiais [teóricos ou empíricos] para fora [dos seus 
respectivos campos científicos] e reestruturando-os dentro da estrutura científica da informação", mediante uma abordagem de "entrelaçamento de conceitos científicos" (WERSIG, 1993, p.238). No nosso exercício, o modelo de rede conceitual constitui o tear no qual iremos entrelaçar os indícios encontrados no território da literatura, os quais representam a produção científica sobre a temática <mediação da informação> no campo da Ciência da Informação no Brasil, em um dado momento histórico. A figura 1, a seguir, mostra a relação entre o atrator conceitual da rede, as variáveis epistemológicas e teóricas e suas aplicações, no contexto da pesquisa sobre ações de informação em curso no Projeto LTi e cujos resultados são compartilhados através do Portal:

Figura 1 - Mediação da informação no LTi: a trama da rede

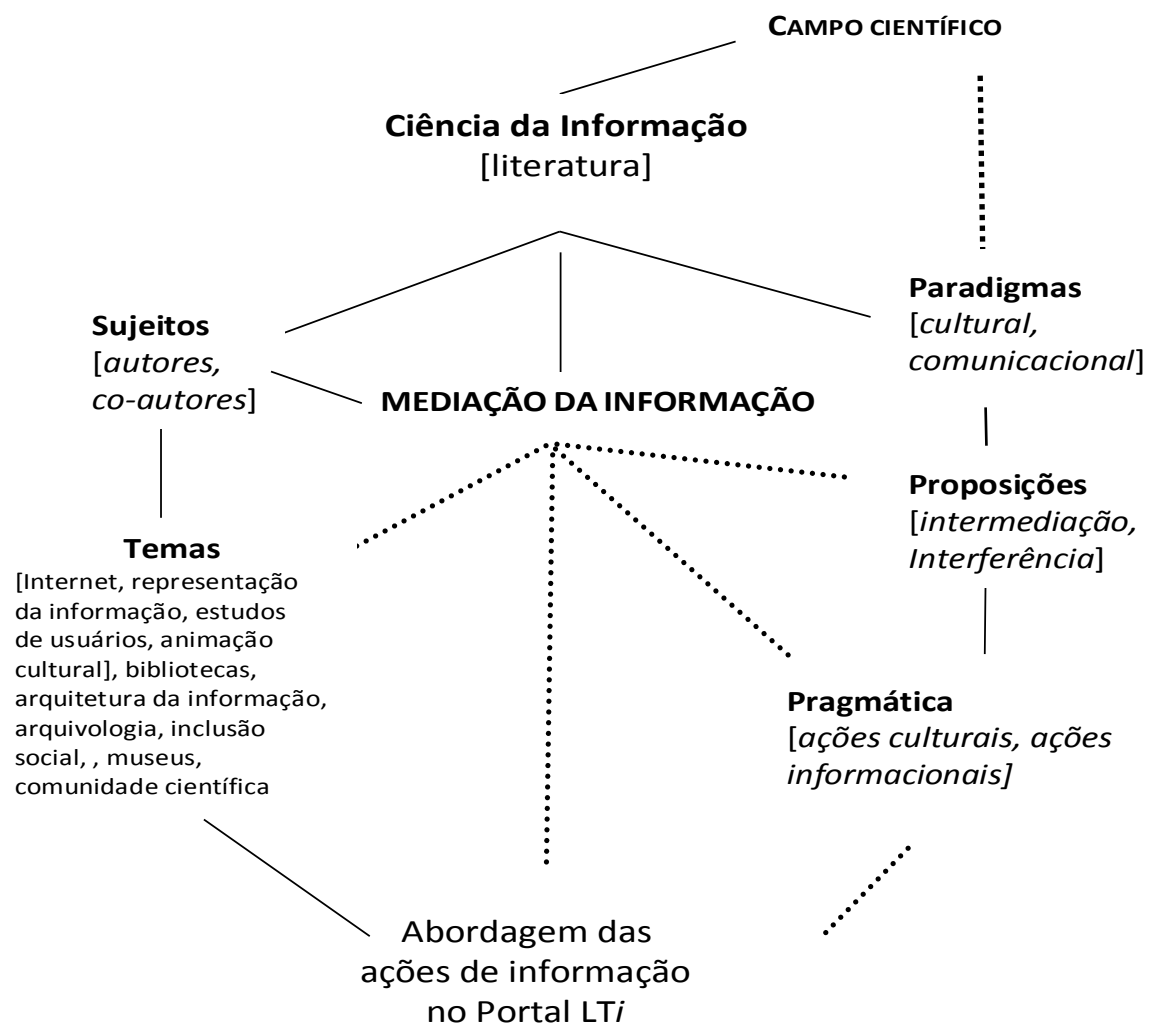

Fonte: Adaptado do modelo de rede conceitual de Wersig (1993).

Na próxima seção, descrevemos e aplicamos o contexto teórico cujos fios conceituais entrelaçamos na trama da rede com a qual caçamos os indícios da temática <mediação da informação> no território da literatura indexada pela Brapci. 


\section{CONTEXTO}

Para Bunge (1980, p. 160), as ciências sociais não oferecem "teorias" sobre seu objeto de estudo, sendo mais comum encontrarmos quadros teóricos, ou "contexto", que ele define como "conjunto de proposições referentes a um mesmo domínio (p.ex., sociedades humanas) contendo certos conceitos (p.ex., os de classe social e anomia) que constituem um grupo homogêneo, no sentido de que todos eles se referem ao mesmo domínio". Sem ser propriamente uma teoria:

[...] Um contexto serve, então, de matéria-prima para elaboração de teorias, uma vez que obteremos cada uma destas selecionando proposições do contexto e, em particular, guardando tão somente aquelas que constituam um conjunto coerente (não contraditório). (BUNGE, 1980, p. 160).

Ademais, o contexto contém a possibilidade da teoria, oferecendo uma explicação para eventos e relações observados em um dado campo de pesquisa e uma previsão para a ocorrência de eventos e relações ainda não observados, com base nos seus próprios princípios explanatórios. Bunge (1980) lembra que embora represente um modo eficaz de explicar os fatos observados, as teorias têm caráter provisório, sendo aceitas na medida de sua coerência semântica e do valor de verdade de suas predições. Nesse sentido, toda teoria, e por extensão todo contexto, em última instância são relativos a uma problemática, o que significa que devem se referir efetivamente à realidade que visa interpretar, pois nas palavras de Popper (1972 apud SARACEVIC, 1996, p. 40) "não somos estudantes de assuntos, mas estudantes de problemas. $E$ os problemas constituem os recortes de qualquer assunto ou disciplina".

Neste exercício de observar um território e tecer ao rede conceitual, abordamos o problema da <mediação da informação> nas ações de informação em curso no Projeto LTi, no contexto do modelo de regime de informação proposto por González de Gómez, e cujos resutados estão disponíveis no Portal. O contexto em que se desenvolve a pesquisa nos permitirá uma primeira aproximação da temática identificada no território da literatura, na perspectiva dos domínios, estratos e modalidades das ações de informação. 


\subsection{Sobre o Regime de Informação}

No contexto cujos fios estamos entrelaçando neste exercício, os termos sociedade da informação e, mais recentemente, sociedade em rede, representam um sistema social que historicamente resulta de inovações nas tecnologias de informação e comunicação, as quais, em conjunto com a relevância da informação, provocaram profundas alterações nos diversos setores da sociedade, embora sua importância e influência seja desigualmente distribuída nos diferentes grupos sociais e regiões geográficas. Nesse contexto, corroboramos com González de Gómez (2003b, 61, Itálico nosso), quando diz a Ciência da Informação tem como objeto de estudo

[os] fenômenos, processos, construções, sistemas, redes e artefatos de informação, enquanto 'informação' for definida por ações de informação, as quais remetem aos atores que as agenciam aos contextos e situações em que acontecem e aos regimes de informação em que se inscrevem.

Assim posto, a autora analisa a informação enquanto ação de informação na perspectiva de que estas constituem um conjunto de estratos heterogêneos e articulados, a saber:

a) de informação (semântico-pragmática), estrato polimórfico que se define nos inúmeros setores da produção social sob a forma de ações narrativas;

b) de meta-informação, estrato regulatório definido nos espaços institucionais do Estado, do campo científico, da educação formal, da legislação e dos contratos;

c) de infra-estruturas de informação, estrato mimeomórfico dos objetos de informação, "definido na indústria e nos mercados das tecnologias, das máquinas e dos produtos" mediante "ações tecnoeconômicas, normas técnicas modelos" (GONZÁLEZ DE GÓMEZ, 2003a, p.34).

Nesse modelo, enquanto ação de informação, a informação se refere a um conjunto de estratos heterogêneos e articulados que se manifestam através de três modalidades:

a) de mediação - quando a ação de informação está aos fins e orientação de uma outra ação. Nesta modalidade, a informação se 
desenvolve no âmbito de outra ação social e seus sujeitos podem ser vistos como 'funcionais', "cujas práticas serão definidas pelo contexto acional em que atua, dentro das múltiplas atividades sociais. [...], seu domínio de constituição é a práxis"² (GONZALEZ DE GOMĖZ, 2003a, p. 36).

b) de formação - quando orientada à informação não como um meio mas como sua finalização, sendo produzida por 'sujeitos heurísticos' ou 'experimentadores', que transformam "os modos culturais de agir e de fazer, nas artes, na política, na ciência, na indústria e no trabalho, iniciando um novo domínio informacional. [...] no domínio da poiesis" ${ }^{3}$ ou da 'forma de vida' de um grupo ou comunidade. (GONZALEZ DE GOMĖZ, 2003a, p. 36).

c) de relação - quando a ação de informação busca intervir em outra ação para dela obter direção e fins, ampliando seu espaço de realização, "o qual alarga nas formas de descrição, da facilitação, do controle ou do monitoramento", sendo realizada por 'sujeitos articuladores' ou' relacionantes', que 'agem no domínio da legein" ${ }^{4}$ (GONZÁLEZ DE GÓMEZ, 2003a, p. 37).

No quadro 1 mostramos a constituição das ações de informação em um dado regime de informação, bem como as relações entre atores (sujeitos executores das ações), meios e fins, conforme apresentado por González de Gómez (2003a, p. 37):

Quadro 1 - Teleologia das ações de informação

\begin{tabular}{|l|l|l|l|}
\hline \multicolumn{1}{|c|}{$\begin{array}{c}\text { Ações de } \\
\text { Informação }\end{array}$} & \multicolumn{1}{|c|}{ Atores } & \multicolumn{1}{c|}{ Atividades } & \multicolumn{1}{c|}{ Finalidades } \\
\hline Ação de Mediação & $\begin{array}{l}\text { Sujeitos Sociais } \\
\text { Funcionais (práxis) }\end{array}$ & $\begin{array}{l}\text { Atividades Sociais } \\
\text { Múltiplas }\end{array}$ & $\begin{array}{l}\text { Transformar o mundo } \\
\text { social ou natural }\end{array}$ \\
\hline $\begin{array}{l}\text { Ação Formativa ou } \\
\text { Finalista }\end{array}$ & $\begin{array}{l}\text { Sujeitos Sociais } \\
\text { Experimentadores } \\
\text { (poiesis) }\end{array}$ & $\begin{array}{l}\text { Atividades Heurísticas } \\
\text { e de Inovação }\end{array}$ & $\begin{array}{l}\text { Transformar o } \\
\text { conhecimento para } \\
\text { transformar o mundo }\end{array}$ \\
\hline $\begin{array}{l}\text { Ação Relacional } \\
\text { Inter-Meta-Pós- } \\
\text { mediática }\end{array}$ & $\begin{array}{l}\text { Sujeitos Sociais } \\
\text { Articuladores e } \\
\text { Reflexivos (legein) }\end{array}$ & $\begin{array}{l}\text { Atividades Sociais de } \\
\text { Monitoramento, } \\
\text { Controle e } \\
\text { Coordenação }\end{array}$ & $\begin{array}{l}\text { Transformar a informação } \\
\text { e a comunicação que } \\
\text { orientam o agir coletivo }\end{array}$ \\
\hline
\end{tabular}

Fonte: GONZÁLEZ DE GÓMEZ, 2003a.

A figura a seguir, descreve e relaciona os estratos, domínios e modalidades das ações de informação, em um dado regime de informação.

\footnotetext{
${ }^{2}$ No campo científico, entendemos a práxis como uma prática profissional em que os atores sociais atuam a partir de uma teoria que é a base para sua ação no mundo.

${ }^{3}$ Entendida como capacidade de produzir alguma coisa, especialmente de forma criativa. No LTi, mediante, especialmente, as ações nos cursos de Graduação.

${ }^{4}$ No sentido em que a ação de informação constituída pelo LTi está atrelada aos fins e orientação da tríplice atuação da universidade pública, qual seja ensino - pesquisa - extensão.
} 
Figura 2 - Relação entre estratos, domínios e modalidades das ações de informação

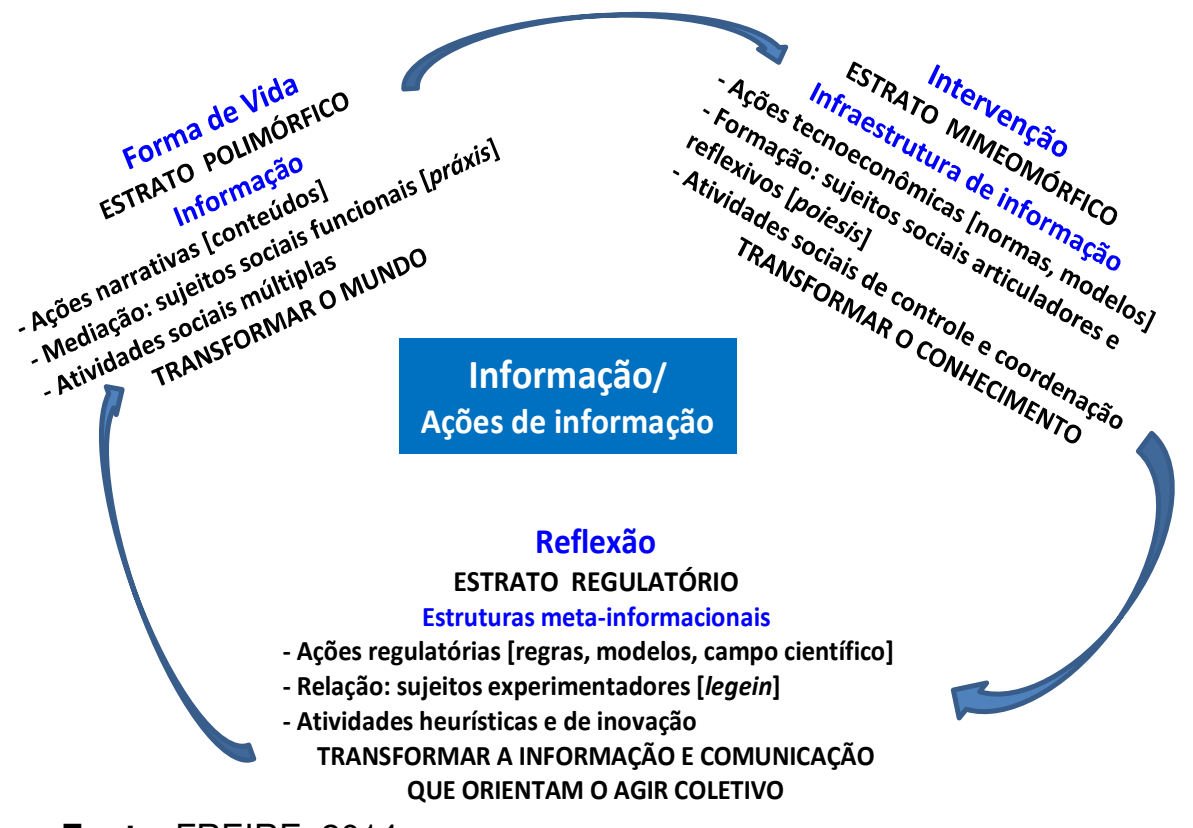

Fonte: FREIRE, 2014.

$\mathrm{Na}$ nossa incursão no território da literatura, observamos os indícios da temática <mediação da informação> de modo a identificar abordagens que subsidiem uma reflexão sobre as ações de mediação da informação no Portal LTi. Como resultado do nosso exercício, reunimos e interpretamos os indícios da temática em nível dos domínios e finalidades das ações de informação, bem como das aplicações epistemológicas, teóricas e pragmáticas. No quadro 4, a seguir, descrevemos os domínios e aplicações das ações de informação em curso no LTi e suas relações com as temáticas identificadas neste exercício: 
Quadro 4 - Organização dos indícios na perspectiva das ações de informação

\begin{tabular}{|c|c|c|c|}
\hline \multicolumn{3}{|c|}{ Domínios e finalidades das ações de informação } & \multirow[t]{2}{*}{ Organização dos } \\
\hline & & indícios & \\
\hline LEGEIN & $\begin{array}{l}\text { Ações relacionais. } \\
\text { [regulatórias] } \\
\text { Atividades } \\
\text { heurísticas e de } \\
\text { inovação. }\end{array}$ & $\begin{array}{l}\text { "Transformar a } \\
\text { informação e a } \\
\text { comunicação que } \\
\text { orientam o agir } \\
\text { coletivo." }\end{array}$ & $\begin{array}{l}\text { Nível epistemológico } \\
\text { CIÊNCIA DA INFORMAÇÃO } \\
\text { BIBLIOTECONOMIA } \\
\text { MEDIAÇÃO }\end{array}$ \\
\hline POIESIS & $\begin{array}{l}\text { Ações formativas } \\
\text { [mimeomórficas]. } \\
\text { Atividades sociais } \\
\text { de controle e } \\
\text { coordenação. }\end{array}$ & $\begin{array}{l}\text { "Transformar o } \\
\text { conhecimento para } \\
\text { transformar o } \\
\text { mundo." }\end{array}$ & $\begin{array}{l}\text { Nível teórico } \\
\text { GESTÃO DA INFORMAÇÃO } \\
\text { REPRESENTAÇÃO DA INFORMAÇÃO } \\
\text { COMUNICAÇÃO CIENTÍFICA } \\
\text { ESTUDOS DE USUÁRIOS }\end{array}$ \\
\hline PRÁXIS & $\begin{array}{l}\text { Ações de mediação } \\
\text { [polimórficas]. } \\
\text { Atividades sociais } \\
\text { múltiplas. }\end{array}$ & $\begin{array}{l}\text { "Transformar o mundo } \\
\text { social ou natural." }\end{array}$ & $\begin{array}{l}\text { Nível pragmático } \\
\text { AÇÃO CULTURAL } \\
\text { BIBLIOTECAS } \\
\text { MUSEUS } \\
\text { POLIITICAS DE INFORMAÇÃO } \\
\text { APROPRIAÇÃO DA INFORMAÇÃO } \\
\text { FORMAÇÃO PROFISSIONAL } \\
\text { ANÁLISE DOCUMENTÁRIA } \\
\text { USO DA INTERNET [Web] } \\
\text { SERVIÇOS DE REFERÊNCIA [on line] } \\
\text { DISSEMINAÇÃO DA INFORMAÇÃO } \\
\text { COMPETÊNCIAS EM INFORMAÇÃO }\end{array}$ \\
\hline
\end{tabular}

Fonte: Dados da pesquisa, 2014. Baseado em González de Gómez, 2003a.

Nesse contexto, as ações de pesquisa (no domínio da poiésis) e as ações de informação (nos domínios da práxis e da legein) integram um mesmo campo de orientações estratégicas e, como consequência, "a política e a gestão da informação formarão parte do mesmo plano decisional e prospectivo ao qual pertence a política e a gestão da ciência e tecnologia" (GONZÁLEZ DE GÓMEZ, 2003b, p. 61). Desse modo, o domínio da práxis lança seus fios conceituais na direção do domínio da poiesis, onde se delineiam as abordagens propriamente teóricas de que tratam os indícios da temática nos artigos recuperados na Brapci. E é deste domínio que, mais adiante, serão lançados os fios à legein - espaço da discussão epistemológica sobre a pertinência e a relevância da produção científica sobre a temática da <mediação da informação>, no campo da Ciência da Informação, no Brasil. 


\section{CONSIDERAÇÕES FINAIS}

O presente exercício teórico-epistemológico consistiu, pois, em buscar e observar os indícios da temática <mediação da informação> no território da literatura idexada pela Brapci, de modo a subsidiar um modelo de abordagem para aplicação às ações de informação em curso no Projeto LTi, em especial dispositivos e artefatos disponibilizados no Portal, de modo a promover o compartilhamento de estoques de informação na Internet.

Assim, tendo em vista os resultados apresentados, consideramos ter atingido nosso objetivo com essa incursão, como se pode observar nos quadros e figuras que apresentamos como resultado do nosso brauseio no campo da pesquisa. Cotejamos os indícios da temática identificados neste exercício com os resultados da pesquisa de Gomes (2010) sobre a produção científica na temática <mediação da informação>, no campo da Ciência da Informação, evidenciando que nossos resultados são pertinentes àqueles.

Destarte, acreditamos ter mais uma vez confirmado o valor do método indiciário e do procedimento de brauseio para pesquisas na literatura, o qual se torna inestimável instrumento de apoio à aplicação da metodologia da pesquisaação, que fundamenta os processos de investigação e intervenção no Projeto LTi.

\section{REFERÊNCIAS}

ALVES, R. Filosofia da ciência: introdução ao jogo e suas regras. 20. ed. São Paulo: Brasiliense, 1994.

ARAUJO, V. M. R. H. de. Sistemas de recuperação da informação: nova abordagem teórico-conceitual. 1994. Tese (Dout. Com. e Cult.). Rio de Janeiro: UFRJ, 1994.

BASE DE DADOS REFERENCIAL DE ARTIGOS DE PERIÓDICOS EM CIÊNCIA DA INFORMAÇÃO - BRAPCI. Disponível em <www.ufpb.brapci.br>.

BUNGE, M. Epistemologia; curso de atualização. 2ed. São Paulo: T. A. Queiroz Ed., 1980 
FREIRE, I. M. Tecendo uma rede conceitual na ciência da informação: tecnologias intelectuais para competências em informação. Informação \& Tecnologia (ITEC), Marília/João Pessoa, v. 1, n.1, p. 130-144, jan./jun., 2014.

. Temática "Responsabilidada social" na literatura da Ciência da Informação indexada pela Brapci. In: ENANCIB - Encontro Nacional de Pesquisa em Ciência da Informação, 28/out. a 1/nov. 2013. XIV ENANCIB. Anais... Florianópolis: UFSC, 20013.

Caracterização das ações de informação no Laboratório de Tecnologias Intelectuais - LTi. Tendências da Pesquisa Brasileira em Ciência da Informação, v. 5, n. 1, 2012.

Responsabilidade social da Ciência da Informação e/ou O olhar da consciência possível sobre o campo científico. 2001. Tese (Doutorado em Ciência da Informação). Rio de Janeiro: UFRJ, 2001.

GINZBURG, C. Mitos, emblemas, sinais: morfologia e história. São Paulo: Cia. das Letras, 1989.

GOMES, H. Tendências de pesquisa sobre mediação, circulação e apropriação da informação no Brasil: estudo em periódicos e anais dos Enancib (20082009). Tendências da Pesquisa Brasileira em Ciência da Informação, v. 3, n. 1, p. 85-99, 2010.

GONZÁLEZ DE GÓMEZ, M. N. As relações entre ciência, Estado e sociedade: um domínio de visibilidade para as questões da informação. Ciência da Informação, v. 32, n. 1, p. 60-76, 2003b.

. Escopo e abrangência da Ciência da Informação e a Pós-Graduação na área: anotações para uma reflexão. Transinformação, v. 15, n. 1, p. 31-43, 2003a.

SAGAN, C. O mundo assombrado pelos demônios: a ciência vista como uma vela no escuro. São Paulo: Cia. das Letras, 1996.

SARACEVIC, T. Ciência da Informação: origem, evolução e relações. Perspectivas em Ciência da Informação, v. 1, n. 1, 1996.

WERSIG, G. Information science: the study of postmodern knowledge usage. Information Processing \& Management, v. 29, n. 2, 1993.

WERSIG, G.; NEVELING, U. The phenomena of interest to information science. The Information Scientist. v. 9, n. 4, 1975.

Title

Mediation of information: a look at LTi portal from literature indexed in Brapci 


\section{Abstract}

Introduction: Presents the results of exploratory research on the scientific literature published on the topic <mediation of information $>$ in the field of information science in Brazil , with a view to identifying theoretical and epistemological approaches.

Objectives: Observe, in the indexed literature on Base Reference Data Journal Articles in Information Science, indications of approaches on the topic <mediation of information> in Brazil.

Methodology: The research used the evidentiary method and procedure brauseio to seek scientific literature on the topic <mediation of information> in Brapci , selecting 13 articles published in nine journals that have the search term in titles and keywords for compose a sample of the territory of the literature, where evidence of approaches were observed .

Results: We note that the articles in the sample exhibit signs of various issues related to $<$ mediation information>, namely: <human mediation>, <read >, <cultural action $>$, <culture>, $<$ Information Literacy >, <information flows >, <information technology and communications >.

Conclusion: We compare the results of our observations with those obtained in the study of Gomes (2010) on production in the theme <mediation information> while using the different methodology adopted in this exercise, finding similarities that both confirm our results ratify as the methodology we adopt.

Key words: Mediation Information. Scientific literature - Brazil. Evidential paradigm. Information regime. Brapci.

\section{Título}

Mediación de la información: una mirada al portal LTi de la literatura indexadas en Brapci

\section{Resumen}

Introducción: Presenta los resultados de una investigación exploratoria en la literatura científica publicada sobre el tema <mediación de la información> en el campo de las ciencias de la información en Brasil, con el fin de identificar los enfoques teóricos y epistemológicos.

Objetivo: Observar, en la literatura indexada en la base de datos de artículos de revistas de referencia en Ciencias de la Información, las indicaciones de los enfoques sobre el tema $<$ mediación de la información > en Brasil .

Metodología: La investigación utilizó el método y el procedimiento probatorio brauseio a buscar literatura científica sobre el tema <mediación de la información> en Brapci , la selección de 13 artículos publicados en revistas nueve que tienen el término de búsqueda en títulos y palabras clave para componer una muestra del territorio de la literatura, donde se observaron evidencias de enfoques.

Resultados: Tomamos nota de que los artículos de los signos de la muestra de exhibición de diversas cuestiones relacionadas con <mediación de la información>, a saber: <mediación humana>, <leído>, <acción cultural >, <cultura>, <Alfabetización Informacional>, <flujos de información >, <tecnologías de la información y las comunicaciones>.

Conclusión: Comparamos los resultados de nuestras observaciones con los obtenidos en el estudio de Gomes (2010 ) sobre la producción en el tema <mediación información> con el uso de diferente metodología adoptada en este ejercicio, encontrando similitudes que corroboran los resultados y que ratifiquen la metodología que adoptamos. 
Isa Maria Freire

Mediação da informação: um olhar sobre o portal LTi a partir literatura indexada na Brapci

Palabras clave: Mediación de la Información. La literatura científica - Brasil. Paradigma probatorio. Régimen de la Información. Brapci.

Recebido em: 15.07.2014

Aceito em: 05.10.2014 